\title{
Development of phosphors with high thermal stability and efficiency for phosphor-converted LEDs
}

Yongchi Tian

Correspondence: ytian@dow.com Dow Electronic Materials, The Dow Chemical Company, 201 Washington Road, Princeton, NJ 08543, USA

\begin{abstract}
This article briefly reviews the developments of the phosphors with high thermal stability and high efficiency for use in phosphor-converted LED (pcLED) packages by Lightscape Materials Inc. (wholly owned by The Dow Chemical Company). The current industry design objectives for pcLED packages are first outlined with emphasis on the emission spectral features required for target brightness and color characteristics for general illumination and back light unit for liquid crystal displays. There is a growing demand on thermal stability of the phosphor emission as the LED package power increases. A phenomenological analysis is described on luminescence loss and its relation to thermal stability of luminescence emission at elevated temperatures, which serves as an empirical guide in the search for new phosphor materials of high thermal stability. Finally, the formulations and luminescence properties of the proprietary carbidonitride and oxycarbidonitride phosphors are discussed.
\end{abstract}

Keywords: Phosphor; LED; Phosphor-converted LED; Carbidonitide; Oxycarbidonitride

\section{Introduction}

The phosphor-converted light emitting diode (pcLED) combines a GaN-based LED with down-converting phosphors and emits light in the visible spectral region. The phosphor beneficially absorbs a portion of the blue or near UV (nUV) LED excitation emission of the native GaN-based LED and broadens the emission spectrum by reemitting at longer wavelengths. Since high brightness (HB) GaN-based LED became available in the mid-1990's, the pcLED has been rapidly developing into many applications, ranging from back light units (BLU) for liquid crystal displays (LCD), to general illumination, and to many specialty and niche lighting areas [1,2]. As pcLED products continue to grow in diversity of package designs, their luminescent features and performance are largely determined by the phosphors used in the packages. The development and availability of the phosphor, therefore, will be a decisive factor to the eventual penetration of pcLEDs into the marketplace.

It had been an industry wish to produce light with LEDs by converting the LED emission into an extended wavelength range in the visible light spectrum ever since semiconductor-based LEDs were developed. The concept of using phosphors to convert the LED emission was demonstrated by an LED chip packaged with a phosphor

(c) 2014 Tian; licensee Springer. This is an Open Access article distributed under the terms of the Creative Commons Attribution License (http://creativecommons.org/licenses/by/4.0), which permits unrestricted use, distribution, and reproduction in any medium, provided the original work is properly credited. 
[3-8]. The earliest demonstrations started in the 1970's, including, for example, a SiCbased, yellow-emitting LED chip packaged with a rhodamine-containing resin to generate orange-red light through down-conversion, and a GaAs-based infrared LED chip packaged with $\mathrm{LaF}_{3}: \mathrm{Tb}$,Er phosphor to generate green light through up-conversion. Although the invention of GaN-based, blue-emitting LEDs brought about the promise of providing a red-green-blue (RGB) light source for full color displays and a white light source for general illumination in the early 1970's, it was not possible to realize that promise until the GaN-based LEDs achieved high brightness performance in mid-1990's.

The emergence of HB GaN-based LEDs triggered an intense search for phosphors that are efficiently excited by blue or nUV light. The initial search included a comprehensive screening of the traditional phosphors discovered and investigated over some 60 years mainly for cathode-ray tube (CRT) and fluorescent lamps. These activities are reflected in the related patent literature [9-11] and summarized in a chapter in a recent book [12]. The search was clearly motivated by, and focused on, white light generation to meet a long-standing industrial goal. As a result, yttrium aluminum garnet doped with cerium (YAG:Ce) was identified as a high efficiency phosphor whose broad band, yellow emission combined with a blue LED emission produces a good white light $[13,14]$. In parallel with the success of YAG:Ce, alkaline earth orthosilicates doped with europium (BOSE) [15] were quickly recognized as an efficient yellow emitter, and adopted in low power pcLED packages ( $<1 \mathrm{Watt} / \mathrm{chip})$ as an alternative for YAG:Ce.

On the other hand, the development of both GaN-based LED chips and pcLED packaging technique continued to move toward increasingly higher power pcLED packages (>1 Watt/chip), driven by the needs for the BLU for large screen TVs and general illumination. However, a unique aspect of conventional pcLED is that the phosphors used in such packages are in physical contact with the LED chip, and the LED chips operate at high temperatures (e.g., in the range of $100^{\circ} \mathrm{C}-150^{\circ} \mathrm{C}$ ). Traditional phosphors (e.g., BOSE) exhibit a significant drop in efficiency at such operating temperatures, limiting the performance of the pcLED devices. This stimulated another round of discovery for phosphor formulations which were required to operate efficiently at high temperatures in high power LED packages. The primary criterion for the phosphor is high thermal stability of luminescence with a lumen maintenance at $150^{\circ} \mathrm{C}$ of $>90 \%$ that at room temperature. Naturally, the search for good host crystals started among refractory materials such as nitrides with a high melting point. As a result, several nitride and oxynitride phosphors were successfully formulated in the early 2000's, and in turn applied to pcLED products. The formulations include the red-emitting $\mathrm{CaAlSiN}_{3}: \mathrm{Eu}$ $[16,17]$ and $\mathrm{Sr}_{2} \mathrm{Si}_{5} \mathrm{~N}_{8}: \mathrm{Eu}[18,19]$, the yellow-emitting Ca- $\alpha$-sialon:Eu [20,21] and $\mathrm{La}_{3} \mathrm{Si}_{6} \mathrm{~N}_{11}$ :Ce [22], the green-emitting $\beta$-sialon:Ce [23] and $\mathrm{SrSi}_{2} \mathrm{~N}_{2} \mathrm{O}_{2}$ :Eu [24]. All these phosphors are converters of blue or nUV light and have high thermal stability. The application of these phosphors not only enabled the pcLED products operating at $>1$ Watt per single chip package, but also significantly expanded the luminescence features of pcLED packages.

There has been an extensive investigation on the nitride and oxynitride phosphors in the last decade. Several review articles have been published that summarize the accomplishments in the field before the year 2011 [12,25-27]. The host crystal structures of these phosphors are based on a network of tetrahedral $\left[\mathrm{SiN}_{4}\right],\left[\mathrm{Si}(\mathrm{O}, \mathrm{N})_{4}\right],\left[\mathrm{AlN}_{4}\right]$ or $[\mathrm{Al}$ 
$\left.(\mathrm{O}, \mathrm{N})_{4}\right]$ which are interconnected to each other through corner-sharing nitrogen atoms. Unlike in most traditional phosphors where the luminescence activators bond to halides or oxygen, the activators, $\mathrm{Eu}^{2+}$ or $\mathrm{Ce}^{3+}$, are coordinated directly with nitrogen atoms. The coordinating bonds thus are more covalent and have higher polarizability than those with halides and oxygen (i.e., Nephelauxetic effect) [28]. This coordinating environment results in a relatively large centroid shift of $4 \mathrm{f}-5 \mathrm{~d}$ transition energy which corresponds to an optical absorption and emission in relatively low energy. Typically, the absorption of Eu2 +-activated nitride phosphors is in blue to nUV spectral region while the emission is in green to red spectral region [12,25-27]. Inspired by the research results, many different crystalline nitrides and oxynitrides have been studied as candidate phosphor host crystals. This article is intended to give a brief overview of the developments of proprietary phosphors for use in pcLED packages by Lightscape Materials Inc. (wholly owned by The Dow Chemical Company). The current industry design targets to be incorporated into pcLED packages will be reviewed with an emphasis on the emission features desired for target brightness and color quality. A phenomenological analysis will be described on luminescence loss at high temperatures, which is related to thermal stability of luminescence emission. Finally, proprietary carbidonitride and oxycarbidonitride phosphor formulations will be discussed.

\section{Requirements for LED Phosphors}

The current pcLED industry is divided mainly into two segments. One manufactures packaged products for BLU for LCD displays and the other produces a large variety of packages for lighting applications. While the metrics and specifications for the pcLED products are different between the two segments, the general requirements for the phosphors are similar. They are listed as follows [12,29]:

1. Desired luminescence features

2. High quantum efficiency

3. Strong absorption in blue and nUV spectral range

4. High thermal stability of luminescence

5. Short emission decay time

6. Long term stability

7. Low cost and low materials usage

8. Environmentally benign composition

Requirement 1, desired luminescence features, includes the spectral features of luminescence excitation and emission. This requirement often serves as the first gate for screening. The requirements 2 to 4 are the intrinsic properties that determine the efficiency performance of the phosphors. While these properties could usually be improved by better crystallization and purifying materials, a threshold value is usually set for each of them at the early stage of development, e.g., quantum efficiency $>60 \%$. Requirement 5, short emission decay time, is related to the emission saturation of the phosphor when it is excited with high photon flux. If a phosphor material with a long decay time is excited with a high photon flux, the emission efficiency can be lower than the value at low power excitation [29]. Requirement 6, long term stability, directly impacts on the life time of the pcLED products which is related to the chemical stability 
and degradation of the phosphor materials under operating conditions. Requirement 7, the cost and low materials usage, is increasingly important as further cost reduction of pcLEDs enables further implementation of solid state lighting. From the phosphor developer's perspective, this requirement can be met by improving in two directions: (1) reduction of the cost of raw materials and processing and (2) reduction of the mass of the phosphor required in pcLED packages to achieve the designed color specifications. Requirement 8, environmentally benign composition, limits the selection of constituent elements and hence the chemical formulations of the phosphors to be devised. Certain elements such as cadmium do not meet this requirement and formulations containing such elements should be ruled out.

Currently available phosphors have enabled pcLED products to deliver lumen performance at the level of fluorescent lamps. However, there is still a significant gap between today's best-in-class product performance and the target performance for fully realizing the potential benefits of LED lighting. For example, most general lighting products have efficiency below $100 \mathrm{~lm} / \mathrm{W}$, while the DOE target for 2020 is $200 \mathrm{~lm} / \mathrm{W}$ to achieve the $19 \%$ energy savings in lighting relative to the year 2010 [1,2]. In addition to the main goal of energy savings, the pcLED product must demonstrate a compelling value in the marketplace before it begins to win sizeable market share from the incumbent products. The value needs to be reflected in the color performance, light output, efficacy, reliability, cost, lifetime, and manufacturability, many of which depend on to what degree the phosphors meet the above seven requirements.

The desired luminescence features of the phosphor would be best defined through the targeted specifications of pcLED packages in which the phosphors are incorporated. The package that combines a blue LED chip and two different phosphors dominates today's pcLED product line. One of the two phosphors emits in the green-yellow and the other in the orange-red wavelength range, which together with the blue LED emission roughly covers the entire visible light spectrum. The green-yellow phosphors are frequently of YAG:Ce type and the red phosphors a nitride type. For lighting, the package products are specified by a set of luminescence properties: color rendering index (CRI), correlated color temperature (CCT) and luminous efficacy of radiation (LER). As the product line has achieved the design diversity to meet the needs for different sectors of lighting, the design objectives for CRI and CCT can be met with the two phosphors. Then, the main driver is LER to approach the final energy savings goal. LER is defined as the luminous flux $(\mathrm{lm})$ of the emission spectrum of the pcLED divided by the optical power (W) of the spectrum [30]:

$$
\text { LER }=\frac{\text { Luminous Efficacy }(\operatorname{lm})}{\text { Optical Power }(W)}=\frac{K m \int S(\lambda) V(\lambda) d \lambda}{\int S(\lambda) d \lambda}
$$

where $K_{m}=683 \mathrm{~lm} / \mathrm{W}, \mathrm{S}(\lambda)$ and $\mathrm{V}(\lambda)$ are the emission intensity and the spectral luminous efficiency as a function of wavelength $\lambda$, respectively. The LER is determined only by the emission spectrum and therefore is largely determined by the emission spectra of the phosphors. Currently, the typical warm white pcLED with CRI $=90$ that combines a blue chip with a YAG:Ce phosphor and a broad band, red-emitting nitride phosphor has an LER of $\sim 310 \mathrm{~lm} / \mathrm{W}$. In contrast, it has been shown that LER values in 
the range of $350 \sim 450 \mathrm{~lm} / \mathrm{W}$ can be accomplished for white pcLED emission spectra with similar CCT and CRI [31-33].

The big gap in LER indicates that there is a compelling need for improvement in phosphor emission features and efficiency performance. One of the sources of lumen deficiency is the portion of the broad red emission band whose radiance quanta are outside of the luminous efficiency curve. Narrowing the bandwidth of the red emission while maintaining its redness is desired. A simulation with a red LED (FWHM $25 \mathrm{~nm}$ ) combined with a blue LED + YAG:Ce demonstrated a white light of LER = $375 \mathrm{~lm} / \mathrm{W}$ at $\mathrm{CCT}=3000 \mathrm{~K}$ and $\mathrm{CRI}=90$ [31-33]. This prompts an approach to use a red line-emitting phosphor in place of the red LED. Recently, a red line-emitting, $\mathrm{Mn}^{4+}$ activated phosphor $\left(\mathrm{K}_{2} \mathrm{SiF}_{6}: \mathrm{Mn}^{4+}\right.$, i.e., $\left.\mathrm{KSF}: \mathrm{Mn}^{4+}\right)$ has been shown to produce a white light at $\mathrm{CCT}=3510 \mathrm{~K}$ and $\mathrm{CRI}=90.9$ in a package with a blue LED and YAG:Ce phosphor $[34,35]$. Compared to the baseline white pcLED with a blue LED and YAG:Ce phosphor, the lumen performance of the KSF: $\mathrm{Mn}^{4+}$-assisted white pcLED is still low. This demonstration shows promise to achieve a high quality white light with a line-emitting red phosphor packaged in a pcLED.

The potential lumen performance of line-emitting phosphors in a white light source can be understood from the experience with fluorescent lamps. In the tri-phosphor luminescent lamp, a combination of three line emitting phosphors was well known to produce white light with high LER and high color quality. The three line emitting phosphors, e.g., in Color 80 Lamps, are $\mathrm{BaMgAl}_{10} \mathrm{O}_{17}: \mathrm{Eu}^{2+},(\mathrm{Ce}, \mathrm{Gd}) \mathrm{MgB}_{5} \mathrm{O}_{10}: \mathrm{Tb}^{3+}$ and $\mathrm{Y}_{2} \mathrm{O}_{3}: \mathrm{Eu}^{3+}$, which emit lines at $\sim 450 \mathrm{~nm}, \sim 540 \mathrm{~nm}$ and $\sim 610 \mathrm{~nm}$, respectively, and they together generate a white light of CRI 80-85 [36]. LER and CRI of such a white light depend critically on the exact wavelength position of the emission lines of the blue and red phosphor whereas they are less sensitive to the wavelength position of the green emission line. To produce a white light with CRI $>80$, the blue emission line is required to be in the range of 440-490 nm and the red emission line in 595-618 nm [37-39]. Learning from the above facts, it is considered a possible path to improving LER with line-emitting phosphors in pcLEDs. With GaN-based LED as the narrow band blue emitter, line emitting green and red phosphors would form a tri-color white light pcLED with high LER and high color quality. Several red line emitting phosphors have been formulated. These include $\mathrm{K}_{2} \mathrm{SiF}_{6}: \mathrm{Mn}^{4+}$ [34], $\mathrm{K}_{2} \mathrm{TiF}_{6}: \mathrm{Mn}^{4+}$ [34], $\mathrm{Na}_{2} \mathrm{SnF}_{6}: \mathrm{Mn}^{4+}$ [40], $\mathrm{Cs}_{2} \mathrm{SnF}_{6}: \mathrm{Mn}^{4+}$ [40], $\mathrm{Na}_{2} \mathrm{SiF}_{6}: \mathrm{Mn}^{4+}$ [41], $\mathrm{Na}_{2} \mathrm{GeF}_{6}: \mathrm{Mn}^{4+}$ [41], and $\beta$-sialon:Pr ${ }^{3+}$ [42]. These phosphors can be excited with blue or nUV light and emit a line spectrum of red color.

For BLU applications, the conventional pcLED packages offer $\sim 72 \%$ of NTSC ratios while next generation products aim at an NTSC ratio of close to 100\%. Moreover, pcLED packages for BLU need to be dimmable over a wider power range while also exhibiting an excellent long term stability. These requirements are related to the emission features and performance of the phosphor, some of which necessitate the development of innovate new phosphor formulations.

\section{Thermal stability of luminescence emission}

Traditional phosphors in CRTs and fluorescent lamps are excited by a relatively low energy flux density. In these operating systems, a relatively large amount of phosphor powder absorbs the excitation energy and is positioned at a distance from the excitation 
source. In contrast, the phosphors in pcLED packages are excited by a significantly higher energy flux density, with much less phosphor powder placed in direct contact with the LED chip. Under these operating conditions, the phosphors not only take up thermal energy directly from the chip (typical junction temperature $\sim 100^{\circ} \mathrm{C}$ ) but also are excited by a high density of photon energy from the chip. Being heated, the crystal of the phosphors is at a high vibrationally excited state, causing the LED excitation energy to be directed more to heat emission through lattice relaxation rather than to the luminescence emission. This relaxation process corresponds to Stokes shift which produces further heating, thereby further reducing the luminescence emission. This is a vicious cycle that precludes applications of the traditional phosphors in pcLEDs. Successful development of high power pcLEDs for general illumination, therefore, requires the development of phosphors that can emit highly efficiently at temperatures of $100^{\circ} \mathrm{C}-150^{\circ} \mathrm{C}$ (Requirement 4 as mentioned above). It is critical that we develop phosphor materials with low thermal quenching at temperatures of $100-200^{\circ} \mathrm{C}$.

Thermal quenching of luminescence happens via a number of photophysical paths in phosphors. In most cases, it is through a crossover from at a high vibrational level in excited state to ground state. There are also other possible paths such as thermallyassisted photoionization and thermally-induced charge transfer. These paths, if they exist, are located at relatively high energy level above a sequence of vibrational levels in excited state, and the thermal quenching thereby would take place in relatively high temperatures. In the case that vibrational transitions dominate the thermal transitions in both ground state and excited state, it is understood that the thermal stability of luminescence is mainly related to the bonding energy of the bonds between the activator atom and the host crystal of the phosphors. Empirically, the bonding energy can be measured by heat of formation, melting point and hardness. Further, the mechanism of electron transition events can be analyzed using a simple energy diagram in configurational coordinates that includes the activator and the surrounding bonds [43]. Consider a configurational-coordinate diagram which includes an activator and its bonds to the host crystal, as shown in Figure 1(a). Upon the absorption of light, the electron undergoes a transition from the ground state to the excited state. The system then relaxes to the lowest vibrational level followed by a radiation transition, Em, to the ground state. These two transition processes correspond to the fluorescence excitation (or absorption, Abs) and emission (Em). The system can also return to the ground state through a crossover step at the crossing point between the excited state and the ground state. This process is more probable when the system is heated and therefore is populated at higher vibrational levels. Following the crossover, the excited electron returns to the lowest vibrational level in the ground state through relaxation in a progression of vibrational levels. The process does not emit light, and instead, generates heat which corresponds to the thermal quenching of luminescence. From this analysis, it is suggested that, to reduce the thermal quenching, the crossing point be located at as high an energy as possible. This would be realized by minimizing the displacement between the equilibrium position at the ground state and at the excited state, i.e., $\Delta R=R_{0}^{\prime}-R_{0}$, as schematically shown in Figure 1(b).

In searching for host crystals with attractive $\Delta \mathrm{R}$, crystalline solids with high hardness were screened for use as phosphor hosts [44]. The hardness and thermal expansion data of several phosphor host related crystals are listed in Table 1. The silicates have 


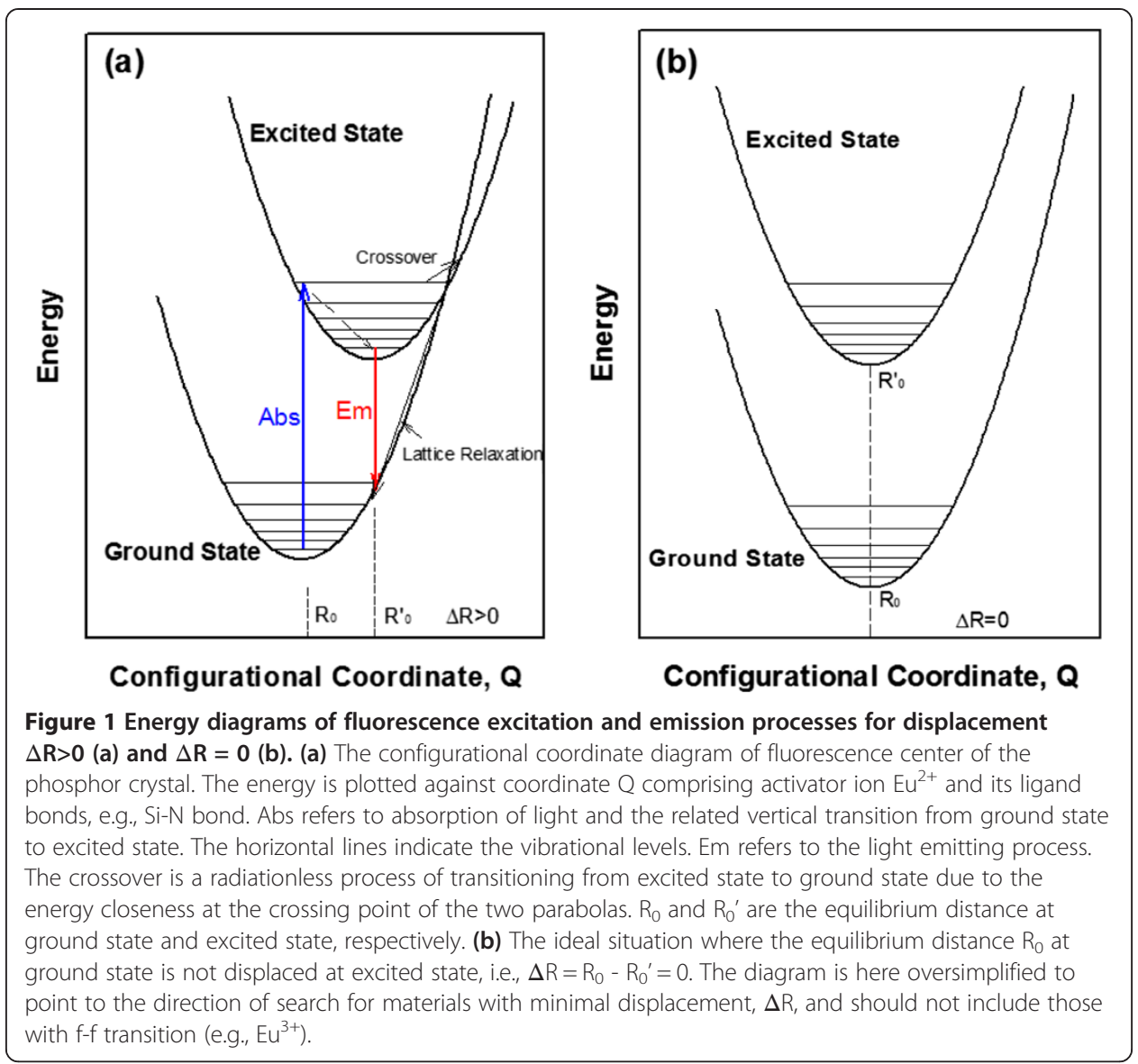

the lowest hardness $(9-13 \mathrm{GPa})$ and the largest thermal expansion $\left(3.3-7 \times 10^{-6} / \mathrm{K}\right)$ values among the selected set. YAG has a higher hardness (13.6 GPa), and a smaller thermal expansion coefficient $\left(\sim 2 \times 10^{-6} / \mathrm{K}\right)$, than the silicates. The hardness of $\mathrm{Si}_{3} \mathrm{~N}_{4}$ (16-20 GPa) and SiC (24.5-28.2 GPa) are significantly higher than that of both silicates and YAG. This suggests that the crystals with structures built of $\mathrm{Si}_{3} \mathrm{~N}_{4}$ and $\mathrm{SiC}$ building blocks tend to have a higher thermal stability of luminescence, and provides some empirical guidance to the search for novel host crystals. The comparison of the thermal quenching profiles of BOSE, YAG:Ce, an oxycarbidonitride green-emitting phosphor $(\mathrm{OCN}-\mathrm{G})$ and a carbidonitride red-emitting $(\mathrm{CN}-\mathrm{R})$ phosphor agrees with the above found trend. As shown in Figure 2, the lumen maintenance in the temperature range of $20-250^{\circ} \mathrm{C}$ is in the order of the CN-R > OCN-G > YAG:Ce > BOSE [45]. It should be pointed out that the thermal quenching of luminescence of phosphors depends not

Table 1 Hardness and thermal expansion values

\begin{tabular}{lll}
\hline Material & Hardness, GPa & Thermal expansion, $\mathbf{1 0}^{\mathbf{- 6} / \mathbf{K}}$ \\
\hline $\mathrm{SiC}$ & $24.5-28.2$ & $\sim 3$ \\
$\mathrm{Si}_{3} \mathrm{~N}_{4}$ & $16-20$ & $2.8-3.2$ \\
YAG & 13.6 & $\sim 2$ \\
Silicates & $9-13$ & $3.3-7$ \\
\hline
\end{tabular}




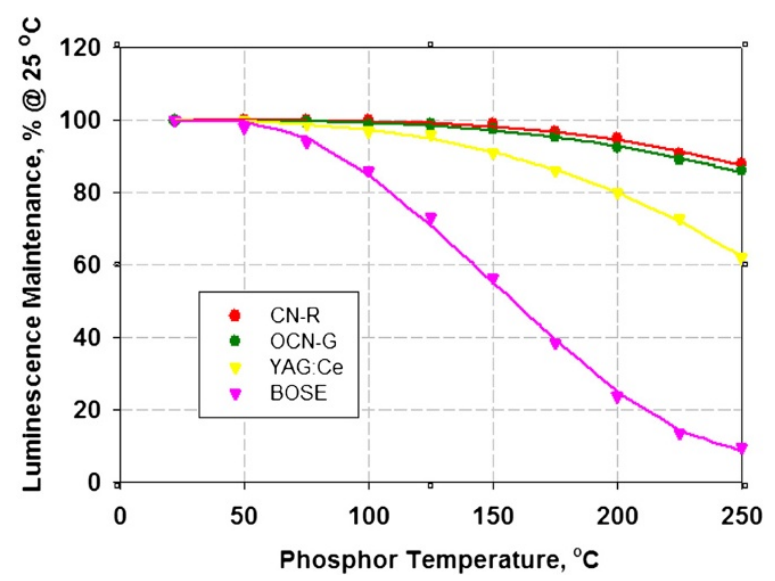

Figure 2 The comparison of the thermal quenching profiles of BOSE, YAG:Ce, an oxycarbidonitride green-emitting phosphor (OCN-G) and a carbidonitride red-emitting (CN-R) phosphor.

only on the host crystals but also on the concentration of the activator [46]. The comparison of the thermal quenching among the phosphors, therefore, needs to be made based on the phosphors with optimal activator concentration. A recent computational chemistry approach revealed that the rigidity of the host crystals of certain phosphors has a correlation with the luminescence efficiency of the phosphors. Measured through Debye temperature $\left(\Theta_{\mathrm{D}}\right)$ of the host crystals, the rigidity was found to be positively proportional to the quantum yield of the related phosphors [47], in good agreement with the above analysis based on the configurational coordinates.

\section{Carbidonitride Phosphors}

Proprietary phosphors with high thermal stability have been pursued by formulating with host crystals composed of the identified high hardness building blocks, i.e., [ $\left.\mathrm{SiN}_{4}\right]$ and $\left[\mathrm{Si}(\mathrm{C}, \mathrm{N})_{4}\right]$. To enhance the hardness, and thus the thermal stability, carbidonitride phosphors have been formulated by carbidation of $\left[\mathrm{SiN}_{4}\right]$ in silicon nitride crystals. Typical nitride crystals are built of silicon nitride tetrahedra which consist of a Si at the center and nitrogen atoms at the four corners. In certain crystals, the tetrahedral building block may include $\left[\mathrm{SiN}_{4}\right]$ and $\left[\mathrm{AlN}_{4}\right]$ [27]. The carbidonitride tetrahedra, in contrast, contain a $\mathrm{Si}$ atom at the center and $\mathrm{C}$ and/or $\mathrm{N}$ atoms at the four corners. The conceptual transformation from $\left[\mathrm{SiN}_{4}\right]$ or $\left[\mathrm{AlN}_{4}\right]$ to $\left[\mathrm{Si}(\mathrm{C}, \mathrm{N})_{4}\right]$ or $\left[\mathrm{Al}(\mathrm{C}, \mathrm{N})_{4}\right]$ is schematically shown in Figure 3. The preparation and structural characterization of several carbidonitride phosphors have been outlined elsewhere [45]. Here a proprietary carbidonitride phosphor will be briefly described.

The proprietary carbidonitride phosphors (A-series phosphors) have been formulated in accordance with the following compositions:

$$
\mathrm{Sr}_{2} \mathrm{Si}_{5} \mathrm{~N}_{8-[(4 \mathrm{x} / 3)+\mathrm{z}]} \mathrm{C}_{\mathrm{x}} \mathrm{O}_{3 \mathrm{z} / 2}: \mathrm{Eu}^{2+}
$$

where $0<x \leqq 5.0,0.06 \leqq x \leqq 0.1$ and $x \neq 3 z / 2$. Typically, they were synthesized by solid state reactions at high temperatures under an inert or reducing atmosphere [48]. The starting materials of $\mathrm{Sr}_{3} \mathrm{~N}_{2}, \mathrm{Si}_{3} \mathrm{~N}_{4}, \mathrm{SiC}, \mathrm{SiO}_{2}, \mathrm{EuN}$ or $\mathrm{Eu}_{2} \mathrm{O}_{3}$ were mixed and fired at temperatures ranging from 1500 to $1800^{\circ} \mathrm{C}$. The emission spectra of two 


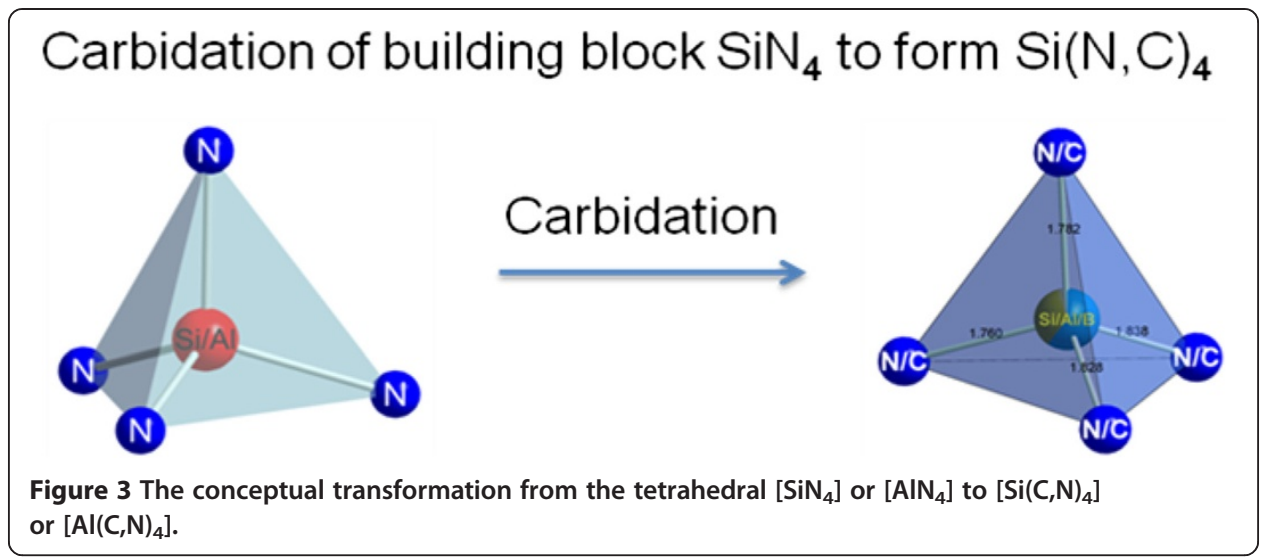

representative formulations, A620 and A630 are given in Figure 4. Activated with $\mathrm{Eu}^{2+}$, the A-series formulations emit red light with a broad bandwidth typically of $\sim 90 \mathrm{~nm}$. The peak wavelength can be tuned within the formulation in the range of 615-650 nm.

The crystal structures of A-series phosphor formulations were studied with X-ray diffraction (XRD). A representative XRD pattern of the A-series phosphors is shown in Figure 5. The phosphor formulations are crystallized in an orthorhombic system belonging to the space group Pmn2 $2_{1}$. A distinctive shift in some diffraction peaks is observed as the carbon content increases. Specifically, as carbon content increases, the diffraction designated (010) is seen to shift gradually toward larger $2 \theta$ angles while the diffraction peak (002) gradually to smaller $2 \theta$ angles, as detailed in Figure 6 . The shifts of the diffractions indicate an anisotropic structural change, with certain interplaner distance decreasing, e.g., (010), and others increasing, e.g., (002). It should be pointed out that the diffraction peaks characteristic of $\mathrm{SiC}$ did not show up in the XRD patterns.

The unit cell coefficients were refined for the A-series phosphor formulations. As seen in Figure 7, as the carbon content increases, the length of both a-axis and c-axis increases while the length of the b-axis decreases. These findings show that the unit

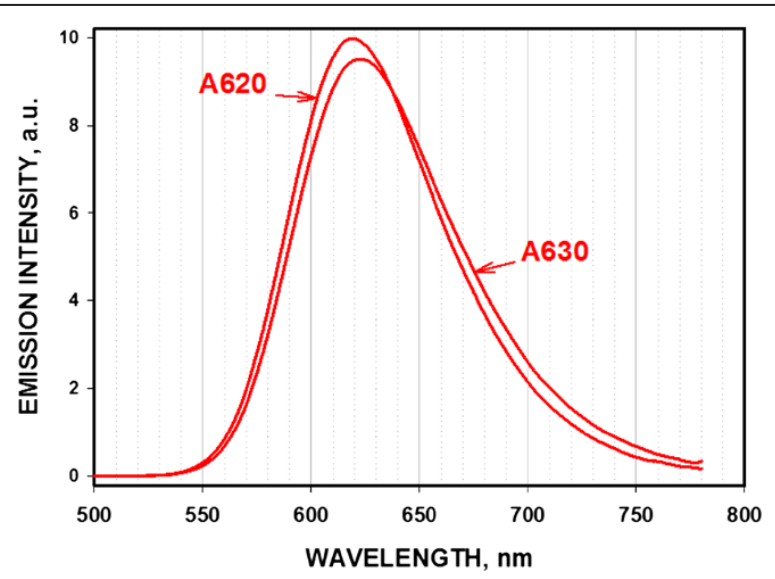

Figure 4 The emission spectra of A620 and A630. 


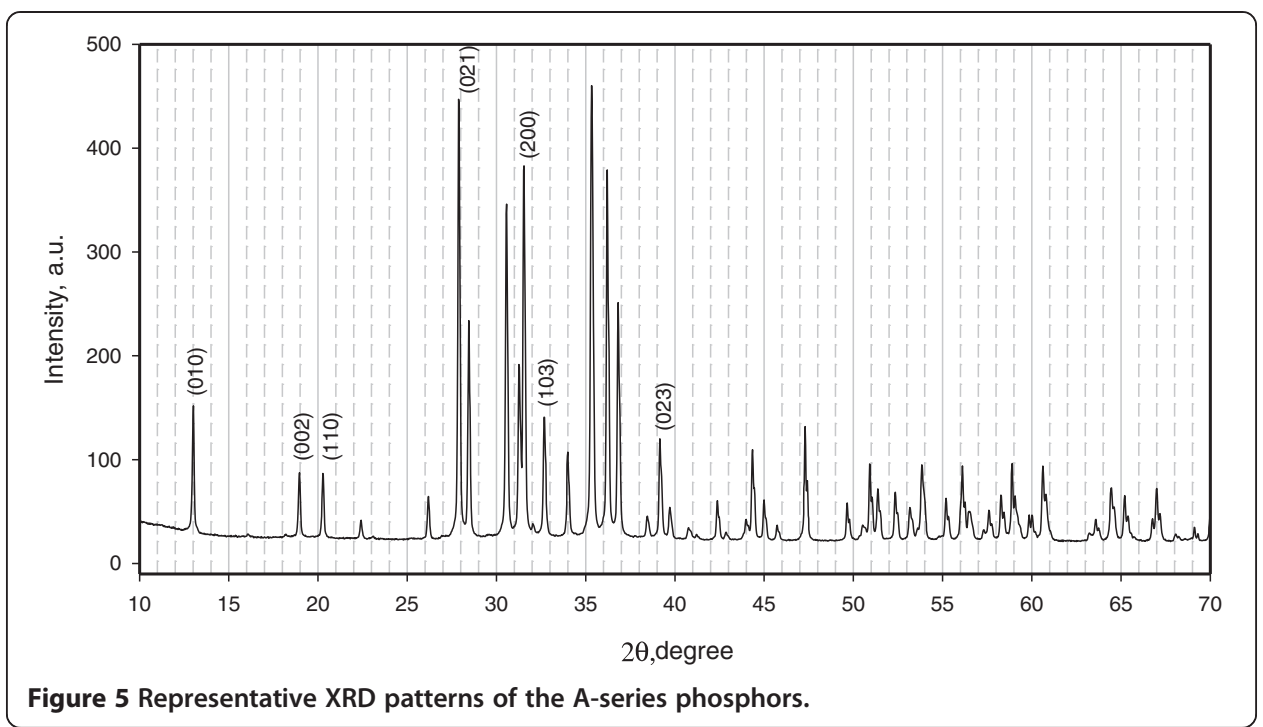

cell structure of the phosphors is deformed as carbon content increases in the lattice, and can be interpreted as follows. The crystal structure is based on a network of corner-sharing $\left[\mathrm{Si}(\mathrm{N}, \mathrm{C})_{4}\right]$ tetrahedra, as determined for the $\mathrm{M}_{2} \mathrm{Si}_{5} \mathrm{~N}_{8}$ type $\left(\mathrm{Pmn} 2_{1}\right)$ structure [45]. The network is fairly rigid and exhibits three-dimensional connectivity. It consists of corrugated layers of condensed three-member rings that are bridged through tetrahedral struts. The metal ions occupy cavities that are enclosed by 3 - and 6-member rings. Carbon atoms occupy three-coordinate $\left(\mathrm{CSi}_{3}\right)$ sites within the corrugated layers, and the oxygen atoms occupy two-coordinate $\left(\mathrm{OSi}_{2}\right)$ sites within the tetrahedral struts. As the content of carbon (and oxygen) increase, the layers expand (unit cell coefficients a and c), while the interlayer distance contracts (unit cell coefficient b). This $\mathrm{a} \uparrow \mathrm{b} \downarrow \mathrm{c} \uparrow$ pattern in lattice deformation with increasing carbon content is consistent with the $\mathrm{C}>\mathrm{N}>\mathrm{O}$ trend in atomic radii.

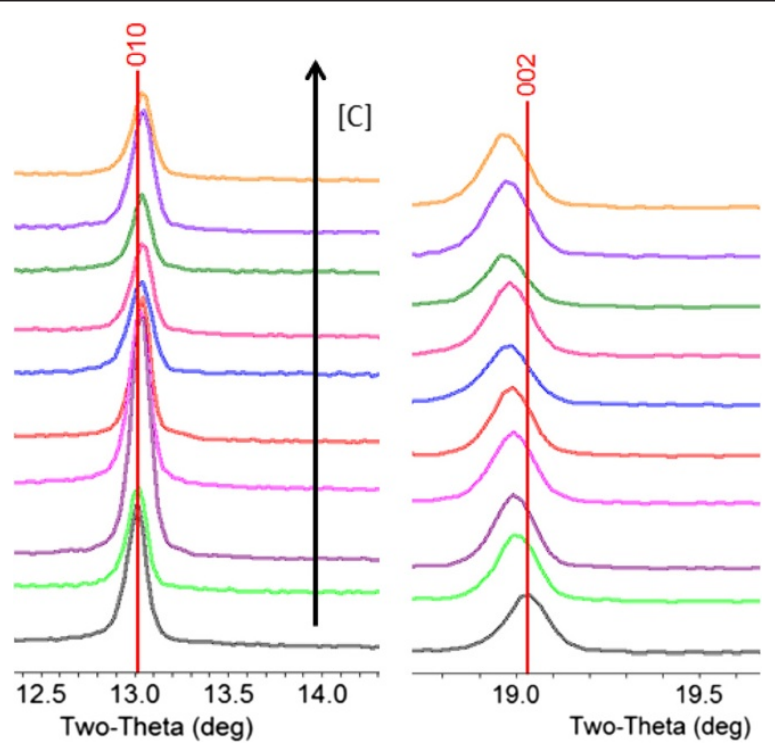

Figure 6 Detailed XRD patterns (010) and (002) of A-series phosphors with different carbon content. 

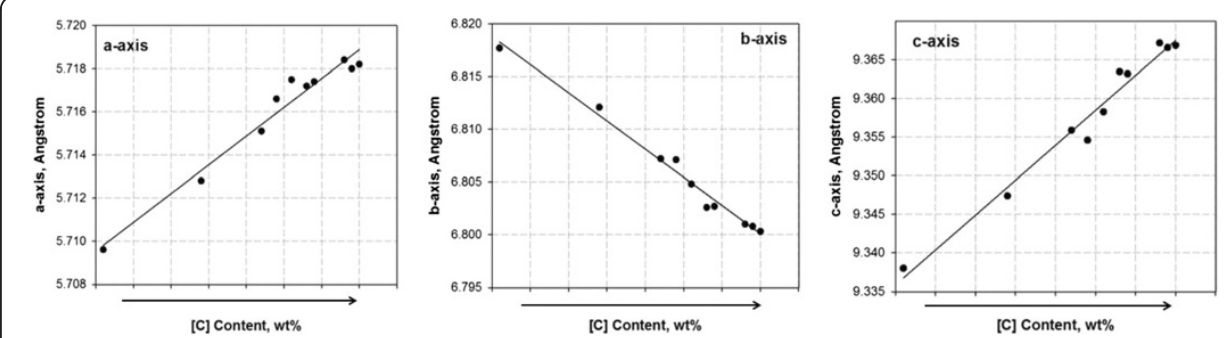

Figure 7 The change of the length of a-, b- and c-axis as a function of carbon content in the A-series formulation.

The lumen maintenance of the A-series phosphor formulations at elevated temperatures shows a $[\mathrm{C}]$-dependence, as displayed in Figure 8. The lumen maintenance increases as carbon content increases within a certain $[\mathrm{C}]$ range in the A-series formulation [49]. This observation agrees with the predicted trend based on the configurational coordinate analysis discussed above, and could be understood as an effect of increased hardness or rigidity.

\section{Oxycarbidonitride Phosphors}

The search for highly thermally stable phosphor formulations with the same guidance was executed for oxycarbidonitride type compositions. An oxycarbidonitride composition has been devised as a phosphor host crystal by the cross substitution of Si-N bonds for $\mathrm{Al}-\mathrm{O}$ bonds based on the compound $\mathrm{Sr}_{7} \mathrm{Al}_{12} \mathrm{O}_{25} . \mathrm{Sr}_{7} \mathrm{Al}_{12} \mathrm{O}_{25}$ is known to be crystallized in a trigonal crystal system with a space group of $\mathrm{P} 3$ [50]. The Al-O framework of $\mathrm{Sr}_{7} \mathrm{Al}_{12} \mathrm{O}_{25}$ could be partially replaced by one based on $\mathrm{Si}-\mathrm{N}$ bonds during a solid state reaction at high temperature:

$$
\mathrm{Sr}_{7} \mathrm{Al}_{12} \mathrm{O}_{25}+\mathrm{xSi}_{3} \mathrm{~N}_{4} \rightarrow \mathrm{Sr}_{7} \mathrm{Al}_{12-\mathrm{x}} \mathrm{Si}_{\mathrm{x}} \mathrm{O}_{25-\mathrm{x}} \mathrm{N}_{\mathrm{x}}
$$

The structure of $\mathrm{Sr}_{7} \mathrm{Al}_{12} \mathrm{O}_{25}$ remains when the substitution is relatively small proportion whereas the structure is not maintained at higher levels of substitution replaced by

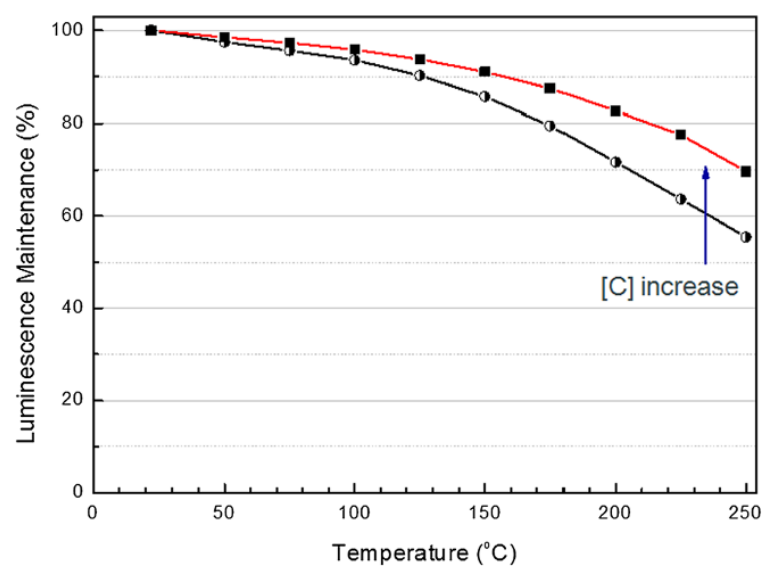

Figure 8 The thermal quenching profiles of A-series phosphors. The lower curve represents the thermal quenching of a formulation with $[C]=0$. 

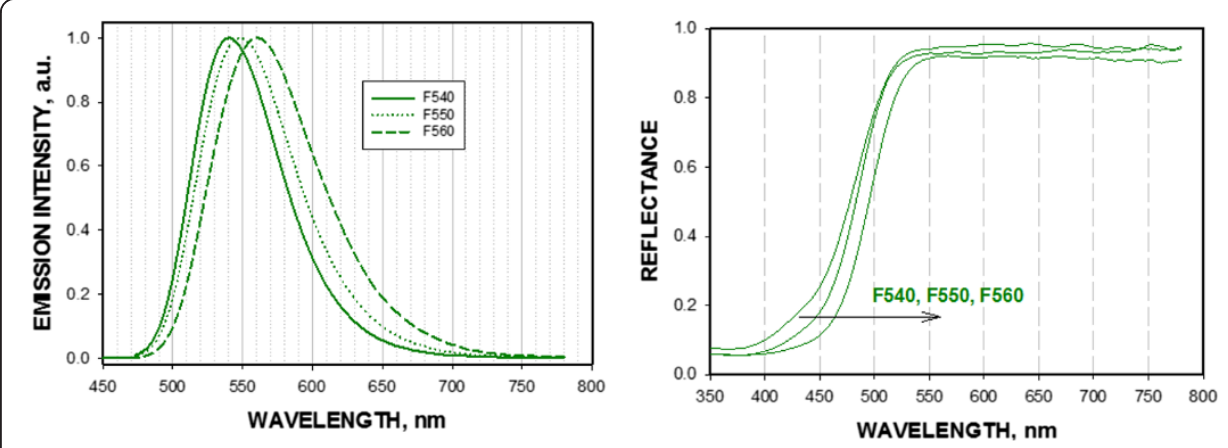

Figure 9 The emission spectra (left) and diffuse reflectance profiles (right) of the phosphors F540, F550 and F560.

$\mathrm{Si}-\mathrm{C}$ bonds. Further, $\mathrm{Al}-\mathrm{N}$ bonds can be replaced by $\mathrm{Si}-\mathrm{C}$ ones, where $\mathrm{Si}$ occupies an $\mathrm{Al}$ site, and $\mathrm{C}$ occupies a $\mathrm{N}$ site in the starting composition expressed below:

$$
\mathrm{Sr}_{7} \mathrm{Al}_{12-\mathrm{x}} \mathrm{Si}_{\mathrm{x}} \mathrm{O}_{25-\mathrm{x}} \mathrm{N}_{\mathrm{x}}+\mathrm{ySi}_{3} \mathrm{~N}_{4}+\mathrm{SiC} \rightarrow \mathrm{Sr}_{7} \mathrm{Al}_{12-\mathrm{x}-\mathrm{y}} \mathrm{Si}_{\mathrm{x}+\mathrm{y}} \mathrm{N}_{\mathrm{x}-\mathrm{y}} \mathrm{C}_{\mathrm{y}}
$$

This solid state chemical scheme was practiced to formulate a family of proprietary green-emitting oxycarbidonitride phosphors (F-series phosphors) expressed as follows [51]:

$$
\mathrm{M}(\mathrm{II})_{7} \mathrm{Al}_{12-\mathrm{x}-\mathrm{y}} \mathrm{Si}_{\mathrm{x}+\mathrm{y}} \mathrm{O}_{25-\mathrm{x}} \mathrm{N}_{\mathrm{x}-\mathrm{y}} \mathrm{C}_{\mathrm{y}}: \mathrm{Eu}
$$

wherein $\mathrm{M}(\mathrm{II})=\mathrm{Mg}, \mathrm{Ca}, \mathrm{Sr}, \mathrm{Ba} ; 0<\mathrm{x} \leqq 12,0<\mathrm{y}<\mathrm{x}$ and $0<\mathrm{x}+\mathrm{y} \leqq 12$. Activated with $\mathrm{Eu}^{2+}$, the F-series phosphors emit efficiently in the green and green-yellow color range, depending on the proportion of the metal ions $\mathrm{Mg}, \mathrm{Ca}, \mathrm{Sr}, \mathrm{Ba}$ in the formulation. The F-series phosphors were prepared by solid state reactions at high temperatures under an inert or reducing atmosphere. The F-series phosphors are crystalline powders with a green or yellow-green body color. The emission spectra together with the respective reflectance profiles of three F-series phosphors, F540, F550 and F560, are shown in Figure 9. The luminescence features of these F-series phosphors are listed in Table 2. Since they have high quantum efficiency, these F-series phosphors are suitable for lighting applications as the main lumen producer. As for BLU application, the desired color point for the green emission is in the range that could increase the color gamut close to $100 \%$ NTSC, which requires more saturated emission.

A representative XRD pattern for an exemplary F-series phosphor is shown in Figure 10 (Left). The XRD pattern was analyzed to contain mainly two phases, an orthorhombic (STRUCTURE I) or triclinic lattice (STRUCTURE II), and a triclinic lattice (STRUCTURE III). The diffraction pattern for the F-series phosphors varies as the content of carbon changes, suggesting an effect of carbon content on the crystal structures. When the content of oxygen is fixed, for example, the diffraction peaks of the STRUCTURE III $\left(\begin{array}{lll}-2 & 1 & 0\end{array}\right)$ are shifted toward higher $2 \theta$ angles, as seen in Figures 10

Table 2 The luminescence features of the phosphors F540, F550 and F560

\begin{tabular}{llll}
\hline Product number & F540 & F550 & F560 \\
\hline Emission Peak & $540 \mathrm{~nm}$ & $548 \mathrm{~nm}$ & $560 \mathrm{~nm}$ \\
Emission Bandwidth (FWHM) & $75 \mathrm{~nm}$ & $80 \mathrm{~nm}$ & $90 \mathrm{~nm}$ \\
CIE 1931 Chromaticity Coordinates & $x=0.347, y=0.615$ & $x=0.383, y=0.590$ & $x=0.436, y=0.550$ \\
\hline
\end{tabular}



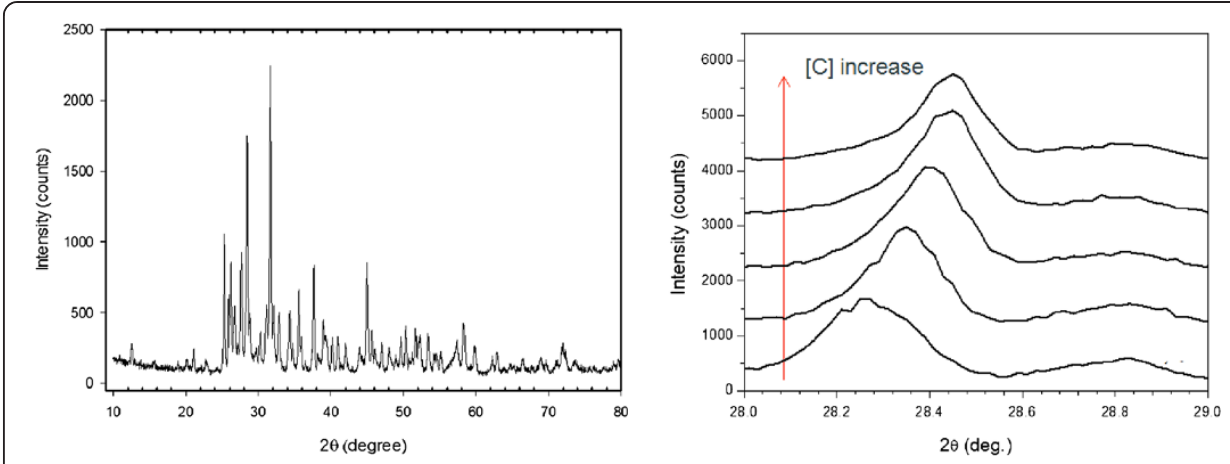

Figure 10 Left: Representative XRD pattern of F-series phosphors. Right: The close-up of the patterns in the $2 \theta=28^{\circ}-29^{\circ}$ of the F-series phosphors with different carbon content.

(Right), as the content of carbon increases, corresponding to the lattice shrinkage due to $[\mathrm{C}]$ increasing in the F-series phosphor.

The lumen maintenance of the F-series phosphors at elevated temperatures was examined. Figure 11 presents the thermal quenching profiles of the F-series phosphors. It can be seen that the lumen maintenance increases with carbon content within a certain $[\mathrm{C}]$ range in the formulation. Once again, this result agrees with the predicted trend based on the configurational coordinate analysis discussed above, and could be understood as an effect of increased hardness or rigidity.

\section{Conclusion}

The investigation of high performance phosphor formulations for pcLED has been driven by the industrial needs for general illumination and BLU for LCD displays. After the initial effort to identify competitive phosphors among the traditional formulations, e.g., YAG: $\mathrm{Ce}^{3+}$ and $\mathrm{MSiO} 4: \mathrm{Eu}^{2+}$, eight criteria were identified for the qualification of phosphor formulations. An empirical analysis on the energetics of photophysical events was conducted based on the energy curves in configurational coordinates that provides guidance in the search for next generation phosphor formulations, i.e., the high hardness of the host crystalline materials is correlated to high thermal stability of the

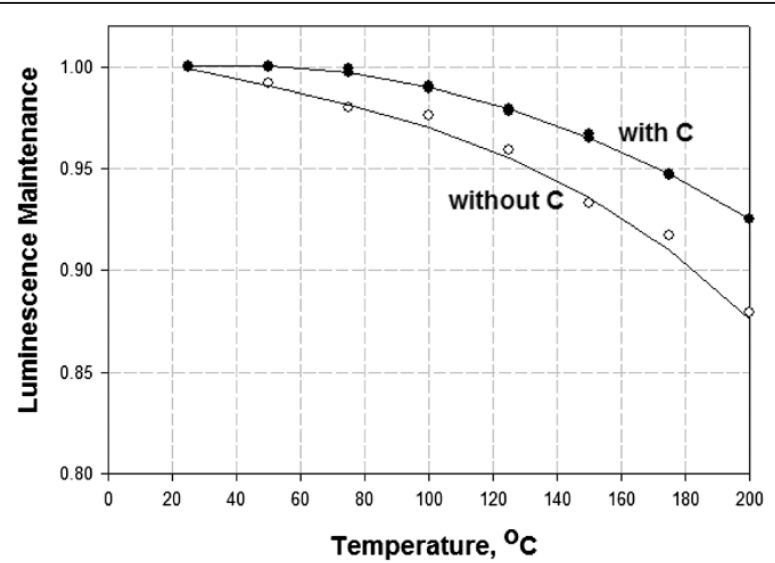

Figure 11 Thermal quenching profiles of the F-series phosphors with different carbon content in the formulation (II). 
luminescence emission. Proprietary phosphor formulations of carbidonitride and oxycarbidonitride have been investigated as phosphors with high efficiency and high thermal stability for use in pcLED devices.

Competing interests

The Dow Chemical Company pays for the processing fees for this article.

\section{Acknowledgement}

The author gratefully appreciates Lora Brehm, Nate Brese, Towhid Hasan, Anne Leugers, Yuan Qiang Li, Mark McAdon, Michael Romanelli, Robert Simms, Alan Thomas and Britt Vanchura at The Dow Chemical Company, whose competence and dedication have created the knowledge outlined in this article. The author also thanks one of the anonymous reviewers for the many valuable suggestions and comments.

Received: 26 February 2014 Accepted: 20 June 2014

Published: 1 August 2014

\section{References}

1. Solid State Lighting Research and Development Multi-Year Program Plan. In April 2013, Prepared for Lighting Research and Development, Office of Energy Efficiency and Renewable Energy U.S. Department of Energy. http://www1.eere.energy.gov/buildings/ssl/.

2. Azevedo IL, Morgan MG, Morgan F: The transition to solid-state lighting. Proc IEEE 2009, 97(3):481-510.

3. Geusic JE, Ostermayer FW, Marcos HM, Van Uitert LG, van der Ziel JP: J Appl Phy 1971, 42(5):1958.

4. Porret F: US Patent $4,038,580$.

5. Potter RM: US Patent $3,529,200$.

6. Amans RL: US Patent $3,510,732$.

7. O'Connor JM, Aina OA: US Patent 5,208,462.

8. Moyer $C D$, Jaskie JE, Legge RN: US Patent 5,334,855.

9. LED phosphors and down-converters patent investigation. In Yole Developpement. 2013.

10. Baretz B, Tischler M: US Patent 6,600,175.

11. Reeh U, Höhn K, Stath N, Waitl G, Schlotter P, Schneider J, Schmidt R: US Patent 6,576,930.

12. Xie R-J, Li YQ, Hirosaki N, Yamamoto H: Nitride Phosphors and Solid-State Lighting. Boca Raton: CRC Press; 2011.

13. Collins WD III, Krames MR, Verhoeckx GJ, van Leth NJ M: US Patent 6,642,652.

14. Shimizu Y, Sakano K, Noguchi Y, Moriguchi T: US Patent 5,998,925.

15. Srivastava A, Comanzo HA, McNulty TF: US Patent 6,621,211.

16. Uheda K, Hirosaki $\mathrm{N}$, Yamamoto $\mathrm{H}$ : Host lattice materials in the system $\mathrm{Ca}_{3} \mathrm{~N}_{2}-\mathrm{AlN}-\mathrm{Si}_{3} \mathrm{~N}_{4}$ for white light emitting diode. Phys Status Solidi a 2006, 203:2712.

17. Uheda K, Hirosaki N, Yamamoto Y, Naito A, Nakajima T, Yamamoto H: Electrochem Solid-State Lett 2006, 9:H22.

18. Hoppe HA, Lutz H, Morys $\mathrm{P}$, Schnick W, Seilmeier A: Luminescence in $\mathrm{Eu}^{2+}$-doped $\mathrm{Ba}_{2} \mathrm{Si}_{5} \mathrm{~N}_{8}$ : fluorescence, thermoluminescence, and upconversion. J Phys Chem Solids 2000, 61:2001.

19. Li YQ, van Steen JEJ, van Krevel JWH, Botty G, Delsing ACA, DiSalvo FJ, de With G, Hintzen HT: Luminescence properties of red-emitting $\mathrm{M}_{2} \mathrm{Si}_{5} \mathrm{~N}_{8}: \mathrm{Eu}^{2+}(\mathrm{M}=\mathrm{Ca}$, Sr, Ba) LED conversion phosphors. J Alloys Compounds 2006, 417:273-279.

20. van Krevel JWH, van Rutten JWT, Mandal H, Hintzen HT, Metselaar R: Luminescence properties of terbium-, cerium-, or europium-doped a-sialon materials. J Solid State Chem 2002, 165:19-24.

21. Xie RJ, Mitomo M, Uheda K, Xu FF, Akimune Y: Preparation and luminescence spectra of calcium- and rare-earth $(\mathrm{R}=\mathrm{Eu}$, Tb, and Pr)-codoped a-SiAlON ceramics. J Am Ceram Soc. 2002, 85:1229-1234.

22. Kijima N, Seto T, Hirosaki N: A new yellow phosphor La3Si6N11:Ce ${ }^{3+}$ for white LEDs. In 216th ECS Meeting, Electrochem Soc 2009, 25:247.

23. Hirosaki N, Xie RJ, Kimoto K, Sekiguchi T, Yamamoto Y, Suehiro T, Mitomo M: Characterization and properties of green-emitting $\beta$-SiAlON:Eu ${ }^{2+}$ powder phosphors for white light-emitting diodes. Appl Phys Lett 2005, 86:211905.

24. Li YQ, Delsing ACA, de With G, Hintzen $H T$ : Luminescence properties of Eu2+-activated alkaline-earth silicon-oxynitride MSi2O2- $\delta \mathrm{N} 2+2 / 3 \delta(\mathrm{M}=\mathrm{Ca}, \mathrm{Sr}, \mathrm{Ba})$ : a promising class of novel LED conversion phosphors. Chem Mater 2005, 17:3242-3248.

25. Xie RJ, Hirosaki N: Silicon-based oxynitride and nitride phosphors for white LEDs-A review. Sci Tech Adv Mater 2007, 8:588-600.

26. Xie R-J, Hirosaki N, Li Y, Takeda T: Rare-earth activated nitride phosphors: synthesis, luminescence and applications. Materials 2010, 3:3777-3793.

27. Zeuner M, Pagano S, Schnick W: Nitridosilicates and oxonitridosilicates: from ceramic materials to structural and functional diversity. Angew Chem Int Ed 2011, 50:7754-7775.

28. Dorenbos $\mathrm{P}: \mathrm{Ce} 3+5 \mathrm{~d}$-centroid shift and vacuum referred $4 \mathrm{f}$-electron binding energies of all lanthanide impurities in 150 different compounds. J. Lumin 2013, 135:93-104.

29. Smet PF, PArmentier AB, Peolman D: Selecting conversion phosphors for white light-emitting diodes. J Electrochem Soc 2011, 158:R37-R54.

30. Ohno Y: Improving the color spectrum to increase LED efficacy, In DOE Solid State Lighting R\&D Workshop, February 2-4: Raleigh. North: Carolina; 2010.

31. Ohno Y: Proc. SPIE 5530, 4th Int. Conf. on Solid State Lighting, Denver, CO 2004,

32. Ohno Y: Optical Engineering 2005, 44(11):30.

33. Ohno Y, Davis W: Proc. SPIE 5941, 5th Int. Conf. on Solid State Lighting, San Diego, CA 2005, 
34. Setlur AA, Radkov EV, Henderson CS, Her JH, Srivastava AM, Karkada N, Kishore MS, Kumar NP, Aesram D, Deshpande A, Kolodin B, Grigorov LS, Happek U: Energy-efficient, high-color-rendering LED lamps using oxyfluoride and fluoride phosphors. Chem Mater 2010, 22:4076-4082.

35. Liao C, Cao R, Ma Z, Li Y, Dong G, Kaniyarakkal N, Sharafudeen, Qiu J: Synthesis of $\mathrm{K}_{2} \mathrm{SiF}_{6}: \mathrm{Mn}^{4+}$ phosphor from $\mathrm{SiO}_{2}$ powders via redox reaction in $\mathrm{HF} / \mathrm{KMnO}_{4}$ solution and their application in warm-white LED. J Am Ceram Soc 2013, 96:3552-3556.

36. Jüstel T, Nikol H, Ronda C: New developments in the field of luminescent materials for lighting and displays. Angew Chem Int Ed 1998, 37:3084-3103.

37. Thornton WA: Luminosity and color-rendering capability of white light. J Opt Soc Am 1971, 61:1155-1163.

38. Koedam M, Opstelten JJ: Light. Res. Technol. 1971, 3:205.

39. Verstegen JMPJ, Radielovic D, Vrenken LE: A new generation of "deluxe" fluorescent lamp, combinging an efficiency of 80 lumens/W or more with a color rendering index of approximately 85. J Electrochem Soc 1974, 121:1627-1631.

40. Arai $\mathrm{Y}$, Adachi S: Optical properties of $\mathrm{Mn}^{4+}$-activated $\mathrm{Na}_{2} \mathrm{SnF}_{6}$ and $\mathrm{Cs}_{2} \mathrm{SnF}_{6}$ red phosphors. J Lumin 2011, 131:2652-2660.

41. Xu YK, Adachi S: Properties of $\mathrm{Na}_{2} \mathrm{SiF}_{6}: \mathrm{Mn}^{4+}$ and $\mathrm{Na}_{2} \mathrm{GeF}_{6}: \mathrm{Mn}^{4+}$ red phosphors synthesized by wet chemical etching. J Appl Phys 2009, 105:013525.

42. Liu TC, Cheng BM, Hu SF, Liu RS: Highly Stable Red Oxynitride $\beta$-SiAION:Pr ${ }^{3+}$ Phosphor for Light-Emitting Diodes. Chem Mater 2011, 23:3698-3705.

43. Leveranz HW: An Introduction to Luminesce of Solids. New York: Dover Publications; 1950.

44. Li Y, Romanelli M, Tian Y: Carbidonitride- and oxycarbidonitride-based phosphors for LED lighting devices. In Proceeding SPIE: Gallium Nitride Materials and Devices VII 2012, 8262:826210-1.

45. Tian Y: Nitride and Oxynitride Based Phosphors for Solid State Lighting. In DOE SSL R\&D Workshop, San Diego, CA, February 2, 2011

46. Bachmann V, Ronda C, Meijerink A: Temperature quenching of yellow $\mathrm{Ce}^{3+}$ luminescence in YAG:Ce. Chem Mater 2009, 21:2077-2084.

47. Brgoch J, DenBaars SP, Seshadri R: Proxies from Ab initio calculations for screening efficient $\mathrm{Ce}^{3+}$ phosphor hosts. J Phys Chem C 2013, 117:17955.

48. Li Y, Romanelli MD, Tian Y: Silicon carbidonitride-based phosphors and lighting devices using the same. US Patent 8,535,566.

49. Li Y, Romanelli MD, Tian Y: Carbidonitride phosphors in LED lighting products. Global phosphor summit, March 19, 2013; New Orleans, LA.

50. Nevskii NN, Glasser LD, lliukhin W, Belov NV: Sov. Phys. Crystallogr. 1979, 24:93.

51. Li Y, Romanelli MD, Tian Y: Oxycarbidonitride phosphors and light emitting devices using the same. US Patent $8,551,361$.

doi:10.1186/s40539-014-0011-8

Cite this article as: Tian: Development of phosphors with high thermal stability and efficiency for phosphor-converted LEDs. Journal of Solid State Lighting 2014 1:11.

Submit your manuscript to a SpringerOpen ${ }^{\circ}$ journal and benefit from:

- Convenient online submission

Rigorous peer review

- Immediate publication on acceptance

- Open access: articles freely available online

- High visibility within the field

- Retaining the copyright to your article

Submit your next manuscript at $\boldsymbol{~ s p r i n g e r o p e n . c o m ~}$ 